\title{
Synthesis conditions of ZBLAN glass for mid-infrared optical components
}

\author{
Jarosław Cimek ${ }^{1,2}$, Xavier Forestier ${ }^{1,3}$, Ryszard Stępień ${ }^{1}$, Mariusz Klimczak ${ }^{1}$, Ryszard Buczyński ${ }^{1,2}$ \\ ${ }^{1}$ Institute of Electronic Materials Technology, Glass Department, Wólczyńska 133, 01-919 Warsaw, Poland \\ ${ }^{2}$ University of Warsaw, Faculty of Physics, Pasteura 5, 02-093 Warsaw, Poland \\ ${ }^{3}$ Warsaw University of Technology, Faculty of Physics, Koszykowa 75, 00-662 Warsaw, Poland
}

Received March 19, 2018; accepted March 31, 2018; published March 31, 2018

\begin{abstract}
We report on successful synthesis of ZBLAN glass. Different purity of zirconium tetrafluoride used for synthesis and fluorinating agents was analyzed to obtain high optical quality glass. Among fluorinating agents we used ammonium bifluoride, xenon difluoride and sulfur hexafluoride. The best results in the form of synthetized glasses have a transmission window extending from 0.2 to $8.0 \mu \mathrm{m}$, which allows to fabricate fibers for mid-infrared applications.
\end{abstract}

Soft glasses attract interest of both science and industry due to their various optical properties as a wide transmission range, high nonlinear refractive index, low phonon energy, and thermo-physical properties as an ability for multiple thermal processing [1]. Several soft glass systems were successfully used for the development of specialty optical fibers [2] as well as microoptical components using a hot embossing method [3]. However, most of the soft glasses suffer from high attenuation when compared with silica glass. In this context, fluoride glasses are extremely unusual. They combine extremely low attenuation, low nonlinear refractive index similar to silica glass, and broadband transmission window from the UV up to 5 micrometers, which exceeds any other known glass system [1].

One of the well-known fluoride glasses and simultaneously the most thermally stable composition is the $53 \mathrm{ZrF}_{4}-20 \mathrm{BaF}_{2}-4 \mathrm{LaF}_{3}-3 \mathrm{AlF}_{3}-20 \mathrm{NaF}$ (ZBLAN) [4]. The ability to incorporate a high concentration of various rare earth metals into the glass matrix allows laser action at wavelengths beyond $3.0 \mu \mathrm{m}$, which is impossible in silica glass [5, 6]. Doped ZBLAN is used often for inscription of Bragg gratings for an all fiber laser system or generating frequency up-conversion [7-9]. Most of the reported ZBLAN fibers are of the step index design. Recently, successful fabrication of photonic crystal fibers (PCF) was reported in 2015 by X. Jiang et. al. [9]. The same group reported next on fiber fabrication from the ZBLAN glass, with nanobores in the core for dispersion shaping and thus improving supercontinuum generation [10]. In 2017 A. Medjouri et. al proposed theoretical approach with filling the PCF air holes for engineering a flattened chromatic dispersion profile [11]. New, all-fiber based systems have also been enabled this way, for supercontinuum generation beyond the ZBLAN transmission in a silica-fluoride-chalcogenide fiber cascade system [12].

The synthesis of fluoride glasses is challenging due to their chemical activity. ZBLAN glasses are very sensitive to moisture even at ambient temperature, which causes degradation of glass on exposure [13]. During synthesis at elevated temperature the fluorine components react with water, producing hydrofluorine acid which evaporates form the batch. The residue oxygen incorporates into the melt, resulting in oxyfluorine materials. Thus melting has to be performed in an inert atmosphere free from oxygen, water and other impurities, which can react with molten glass. Synthesis cannot be performed in sealed silica ampoules like the chalcogenide glasses, neither, due to creation of gaseous $\mathrm{SiF}_{4}$. The only known method for ZBLAN melting is to use gold or platinum crucibles. The presence of any impurities will either lead to incorporating them into the glass network or depleted fluorine content in the glass. An insufficient content of fluorine can lead to zirconium reduction and formation of $\mathrm{ZrF}_{3}$. This compound is not a glass former thus will be revealed as black impurities.

In this work we investigate the influence of purity of the main component - zirconium tetrafluoride, and the effect of addition of fluorinating agents, such as ammonium bifluoride, xenon difluoride and sulfur hexafluoride, on final glass quality.

Glasses were synthetized using a conventional melt and quench technique. The entire process was performed in a glove box with a nitrogen atmosphere, where oxygen and water contamination was below $5 \mathrm{ppm}$. For synthesis we used zirconium tetrafluoride with a purity of $99.9 \%(3 \mathrm{~N})$ and $99.999 \%(5 \mathrm{~N})$, the remaining substrates and purities were: $\mathrm{BaF}_{2}-99.999 \%, \mathrm{LaF}_{3}-99.99 \%, \mathrm{AlF}_{3}-99.95+\%$, $\mathrm{NaF}-99.99 \%$. As an additive for enriching the melted glass with fluorine, various fluorinating agents were used including, $\mathrm{NH}_{4} \mathrm{~F}_{2} 99.999 \%, \mathrm{XeF}_{2} 99.5 \%$ and gaseous $\mathrm{SF}_{6}$ (4.0). Each component was weighed to obtain the desired composition of glass with a final weight of $30 \mathrm{~g}$ and then ground in an agate mortar to obtain homogenous powder. Raw materials were then transferred to a platinum crucible covered with a lid and inserted in a cold furnace. 
During melting at high temperature, the glass was stirred twice by delicate shaking of the crucible. All melting was performed for 6 hours from the insertion of a loaded crucible into the furnace, melting at $850^{\circ} \mathrm{C}$, to the final casting onto a preheated brass form. The hot form was transferred to another furnace and the glass was annealed from $280^{\circ} \mathrm{C}$ down to room temperature at a rate of $0.5^{\circ} \mathrm{C}$ per minute.

A total of 8 glass syntheses were performed with different zirconium tetrafluoride purity and various fluorinating agents. Time and temperature were maintained identical for all melts. Obtained materials differed depending on the used substrates, from a ceramic-like material to glass with a large number of visible, black inclusions, grey colored semitransparent glass to clear, high quality glass. The results of using different $\mathrm{XrF}_{4}$ purity and fluorinating agents are presented in Table 1.

Table 1. Glass quality obtained from using different zirconium tetrafluoride purity and fluorinating agent.

\begin{tabular}{|c|c|c|}
\hline \multirow{2}{*}{$\begin{array}{c}\text { Fluorinating } \\
\text { agent }\end{array}$} & \multicolumn{2}{|c|}{$\mathrm{XeF}_{4}$ purity } \\
\hline & $99.9 \%$ & $99.999 \%$ \\
\hline None & $\begin{array}{l}\text { Grey coloured glass } \\
\text { Lot of black solid } \\
\text { impurities }\end{array}$ & $\begin{array}{l}\text { Transparent glass } \\
\text { Minor black solid } \\
\text { impurities }\end{array}$ \\
\hline $\mathrm{NH}_{4} \mathrm{~F}_{2}$ & $\begin{array}{c}\text { Grey coloured glass } \\
\text { Black solid impurities }\end{array}$ & $\begin{array}{c}\text { Grey coloured glass } \\
\text { Black solid impurities }\end{array}$ \\
\hline $\mathrm{XeF}_{2}$ & $\begin{array}{l}\text { Grey coloured glass } \\
\text { Minor black solid } \\
\text { impurities }\end{array}$ & $\begin{array}{l}\text { Clear transparent } \\
\text { glass }\end{array}$ \\
\hline $\mathrm{SF}_{6}$ & $\begin{array}{c}\text { Grey ceramic like } \\
\text { material }\end{array}$ & $\begin{array}{l}\text { Clear transparent } \\
\text { glass }\end{array}$ \\
\hline
\end{tabular}

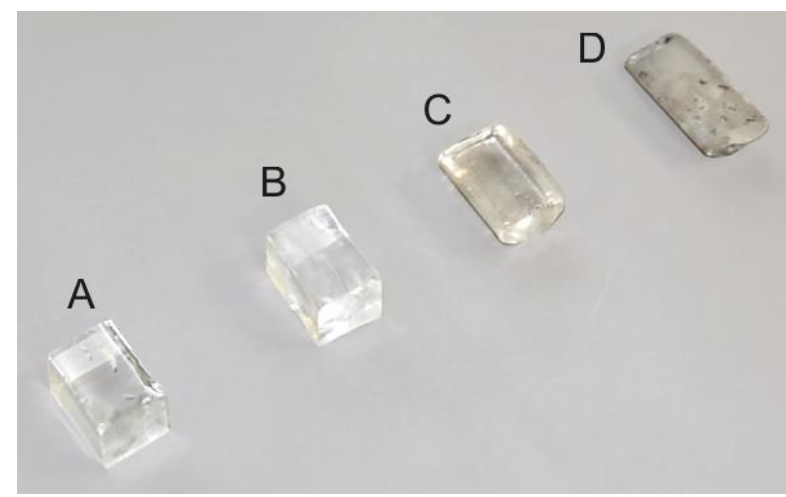

Fig.1. Visual comparision of ZBLAN glasses synthetized form different $\mathrm{ZrF}_{4}$ purity and fluorinating agent. A $\left(\mathrm{ZrF}_{4} 99.999 \%, \mathrm{SF}_{6}\right), \mathrm{B}\left(\mathrm{ZrF}_{4}\right.$ 99.999\%, $\left.\mathrm{XeF}_{2}\right), \mathrm{C}\left(\mathrm{ZrF}_{4} 99.9 \%, \mathrm{XeF}_{2}\right), \mathrm{D}\left(\mathrm{ZrF}_{4} 99.9 \%, \mathrm{NH}_{4} \mathrm{~F}_{2}\right)$.

In case of using $3 \mathrm{~N}$ zirconium tetrafluoride overall glass quality was poor, even with addition of different fluorinating agents. Glasses were semi-transparent with grey color. Impurities in form of black flakes were also present in the mass. In the case of applying $5 \mathrm{~N}$ zirconium tetrafluoride, the results were improved. Only in the case of using ammonium bifluoride, the obtained sample had a grey color and contained visible, black impurities. The best results were obtained with using xenon difluoride and sulphur hexafluoride as fluorinating agents. In both cases, the glasses were transparent and free of any impurities determinable with naked eye. Exemplary glass blocks from different synthesis is shown in Fig.1.

The optical properties of the developed ZBLAN glass were investigated with transmittance and refractive index measurements. Transmittance for a $2 \mathrm{~mm}$ thick sample was measured with two spectrophotometers: a Varian Carry 5000 covering wavelengths from $175 \mathrm{~nm}$ to $3300 \mathrm{~nm}$ and Bruker IFS $113 \mathrm{~V}$ with $2 \mu \mathrm{m} \div 10 \mu \mathrm{m}$ coverage. High transmittance of over $80 \%$ for a $2 \mathrm{~mm}$ thick sample of ZBLAN glass is recorded in the range of $300 \div 6700 \mathrm{~nm}$ (Fig. 2). The transmission tail covers wevevengths up to $8.8 \mu \mathrm{m}$. The obtain transmission properties are similar to those of prevously reported high quality ZBLAN glass [9].

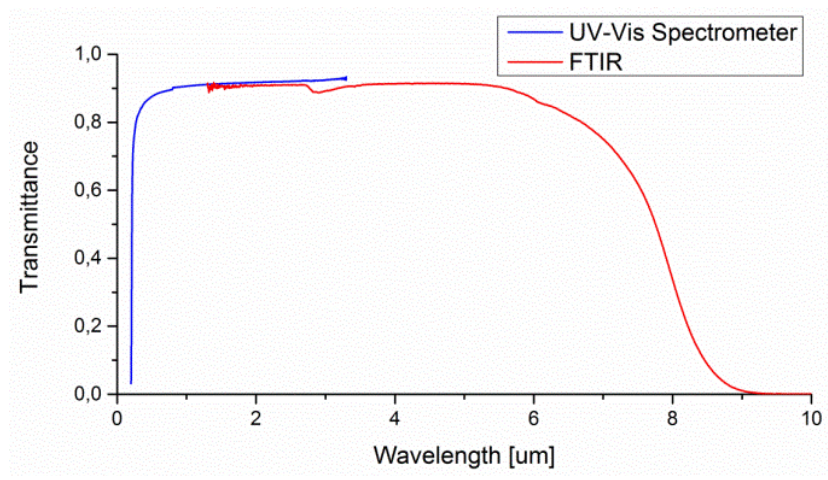

Fig. 2. Transmittance of optimized ZBLAN glass developed with an $\mathrm{XeF}_{2}$ fluorinating agent for a $2 \mathrm{~mm}$ thickness sample.

The phase refractive index was determined by retrieving it from group refractive index measurement in a Michelson interferometer setup [14]. We used an Ocean Optics HL-2000 Halogen lamp as a light source, and Thorlabs CCS200/M and Avantes AvaSpec NIR256-1.7 spectrometers to record interferograms over $200 \div 1000 \mathrm{~nm}$ and $1000 \div 1700 \mathrm{~nm}$ wavelengths, respectively. The refractive index characteristic, compared to the data taken from [15], is presented in Fig.3. The refractive index of ZBLAN glass differs, compared to the literature, due to differences in synthesis parameters, like time and temperature. During synthesis some of the zirconium fluoride can evaporates, which causes changes in the final glass properties. With optimization of synthesis parameters, these changes should be minimal and allow for obtaining identical glasses from melt to melt.

We show that with the proposed method, a ZBLAN glass with different material dispersion can be obtained. Since the thermo-physical properties of ZBLAN glasses with 
various compositions are very similar, they can be jointly thermally processed. Therefore nanostructured microoptical components with various functionalities, such as axicons, microlenses, or diffractive optical components can be obtained with the stack-and-draw approach proposed earlier $[16,17]$.

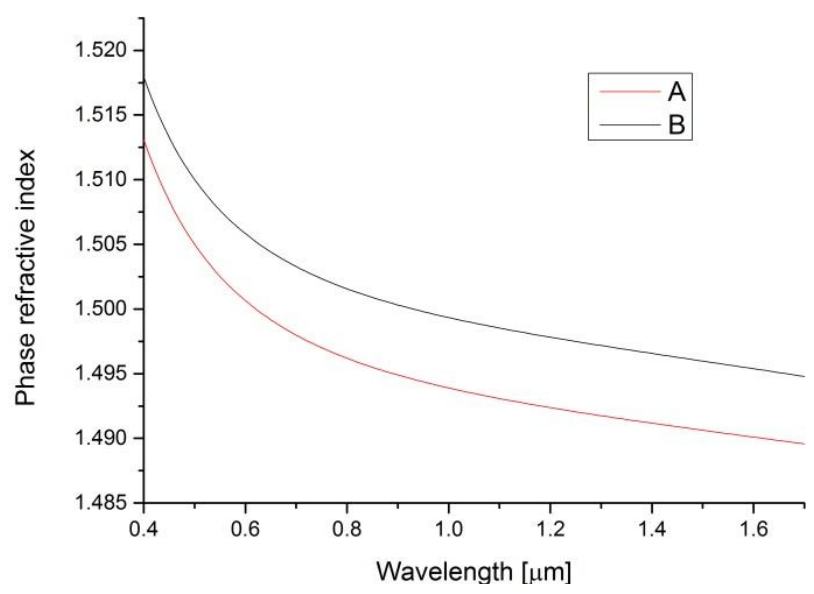

Fig. 3. Phase refractive index of synthetized ZBLAN glass, A - This work, B - values based on [15].

In conclusions, we have determined the key conditions for obtaining clear, high quality fluoride, ZBLAN glass. The ultrahigh purity substrates are essential for successful synthesis. Additionally, to obtain clear glass, fluorinating agents have to be also applied. We achieved positive results with xenon difluoride and sulphur hexafluoride. The obtained glass samples exhibited transmittance spanning from 0.2 to $8.0 \mu \mathrm{m}$, and the refractive index was comparable to that of previously reported fluoride glasses. Such materials are suitable for further processing to midinfrared lenses and photonic crystal fibers.

This work was supported by grant HARMONIA of National Science Centre in Poland UMO2013/10/M/ST3/00708 and European Training Network H2020-MSCA-ITN-2016 Grant No 722380, SUPUVIR: Supercontinuum broadband light sources covering UV to IR applications

\section{References}

[1] R. Stępień, J. Cimek, D. Pysz, I. Kujawa, M. Klimczak, R. Buczyński, Soft glasses for photonic crystal fibers and microstructured optical components, Opt. Eng. 53, 071815 (2014).

[2] D. Pysz, I. Kujawa, R. Stępień, M. Klimczak, A. Filipkowski, M. Franczyk, L. Kociszewski, J. Buźniak, K. Haraśny, R. Buczyński, Bull. Pol. Acad. Sci.-Tech. Sci., 62(4), 667 (2014).

[3] R. Kasztelanic, I. Kujawa, R. Stępień, K. Haraśny, D. Pysz, R. Buczyński, Infrared Phys. Technol. 61, 299 (2013).

[4] C.T. Moynihan, "Crystallization Behavior of Fluorozirconate Glasses" in Halide Glasses for Infrared Fiberoptics (NATO ASI Series; Series E: Applied Sciences, Springer, Dordrecht 1987)

[5] M.R. Majewski, R.I. Woodward, S. D. Jackson, Opt. Lett. 43, 971 (2018).
[6] G. Bharathan, R.I. Woodward, M. Ams, D.D. Hudson, S.D. Jackson, A. Fuerbach, Opt. Expr. 25, 30013 (2017).

[7] Y. Shen, Y. Wang, H. Chen, K. Luan, M. Tao, J. Si, Sci. Rep. 7, 14913 (2017).

[8] J. Méndez-Ramos, P. Acosta-Mora, J.C. Ruiz-Morales, T. Hernández, M.E. Borges, P. Esparza, J. Lumin. 143, 479 (2013).

[9] X. Jiang, N.Y. Joly, M.A. Finger, F. Babic, G.K.L. Wong, J.C. Travers, P.St.J. Russell, Nat. Photonics 9, 133 (2015).

[10]X. Jiang, N.Y. Joly, M.A. Finger, F. Babic, M. Pang, R. Sopalla, M.H. Frosz, S. Poulain, M. Poulain, V. Cardin, J.C. Travers, P.St.J. Russell, Opt. Lett. 41, 4245 (2016).

[11]A. Medjouri, E.B. Meraghni, H. Hathroubi, D. Abed, L.M. Simohamed, O. Ziane, Optik 135, 417 (2017).

[12]D.C. Tee, N. Tamchek, C.H. Raymond Ooi, IEEE Photon. J. 8, 4500713 (2016).

[13] Y. Dai, K. Takahashi, I. Yamaguchi, J. Mater. Sci. Lett. 12, 1648 (1993).

[14]P. Hlubina, Opt. Commun. 193, 1 (2001).

[15]F. Gan, J. Non-Cryst. Sol. 184, 9 (1995).

[16]A. Filipkowski, B. Piechal, D. Pysz, R. Stepien, A. Waddie, M.R. Taghizadeh, R. Buczynski, Opt. Lett. 40, 5200 (2015).

[17]R. Kasztelanic, A. Filipkowski, D. Pysz, R. Stepień, A.J. Waddie, M.R. Taghizadeh, R. Buczynski, High resolution Shack-Hartmann sensor based on array of nanostructured GRIN lenses, Opt. Express 25, 1680 (2017). 